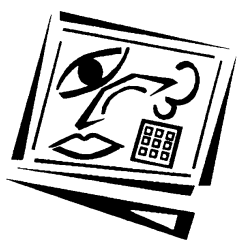

\title{
Elementary school students' attitudes and self-efficacy of using PDAs in a ubiquitous learning context
}

\author{
Pei-Shan Tsai, Chin-Chung Tsai \\ National Taiwan University of Science and Technology \\ Gwo-Haur Hwang \\ Ling Tung University
}

\begin{abstract}
The purpose of this study was to develop an attitude and a self-efficacy survey of using PDAs in ubiquitous learning (u-learning) environments for elementary school students. The sample of this study included 414 third-grade to sixth-grade students (age 9-12 years) in Taiwan who had experience using PDAs for u-learning. The results indicate that the students, in general, had positive attitudes and adequate self-efficacy in terms of using PDAs for u-learning. Gender differences existed only in the students' self-efficacy of using PDAs for Internet related functions, with the male students expressing higher confidence in using PDAs for Internet-related functions than the female students. In addition, the students in lower grades (third and fourth-graders; age 9-10 years) tended to use PDAs more frequently and to have more positive perspectives of PDAs than the higher grade students (fifth and sixth-graders; age 11-12 years). Furthermore, for predicting students' attitudes toward using PDAs for ulearning, students' confidence in using PDAs for general purposes was more important than their confidence in using PDAs to perform Internet functions.
\end{abstract}

\section{Introduction}

Recently, many studies have investigated the nature of learners' use of information technology in various learning environments. The studies by Churchill and Churchill (2008), Federico (2000), Liaw (2002), Tsai and Tsai (2003) and Peng, Tsai and Wu (2006), explored learner characteristics such as perceptions, attitudes and self-efficacy towards information technology in Internet based learning environments. In addition, many studies have revealed that learners' attitudes (e.g. Oral, 2008; Tsai, Lin \& Tsai, 2001) and self-efficacy (e.g. Chu \& Tsai, 2009; Tsai \& Tsai, 2003; Wang \& Wang, 2008) toward computers, Internet and mobile devices influence their usage. For example, Wang and Wang (2008) developed a mobile computing self-efficacy instrument to explore learners' self-efficacy regarding mobile computers, such as PDAs and handheld computers, and found that learners with higher self-efficacy in terms of mobile computers have favorable perspectives towards using them.

Comparatively more studies have explored the relationships between learners' attitudes and self-efficacy toward computers, the Internet and Internet based learning (e.g. Susskind, 2008; Torkzadeh, Thomas \& Dyke, 2002; Peng et al., 2006; Wu \& Tsai, 2006). For example, $\mathrm{Wu}$ and Tsai (2006) found that students' attitudes toward the Internet were correlated highly with their Internet self-efficacy. In other words, learners with higher self-efficacy regarding information technology may have more positive 
attitudes toward information technology. Therefore, these studies (e.g. Susskind, 2008; Torkzadeh et al., 2002; Peng et al., 2006; Wu \& Tsai, 2006) also showed that learners' attitudes and self-efficacy regarding information technology have been important issues in educational research.

Moreover, wireless network-related technology (e.g. u-computing, wireless communications and sensor) and mobile devices has promoted the research issues, not only from e-learning to m-learning (mobile learning; Dyson, Litchfield, Lawrence, Raban, \& Leijdekkers, 2009), but also from m-learning to u-learning (context aware, ubiquitous learning; Hwang, Tsai \& Yang, 2008). Hwang et al. (2008) defined ulearning as providing the right content for the right learners, at the right time, in the right place and in the right context. The main characteristics of $\mathrm{u}$-learning are: learners do not break off their learning; learners can access their documents from anywhere and at anytime; learners can get information immediately; learners can interact with others such as experts, teachers and peers, and learners can learn in real, authentic situations (Ogata \& Yano, 2004). Numerous studies have developed u-learning systems with personal digital assistants (PDAs) as mobile devices, and have evaluated their effect on learners' performance (e.g. El-Bishouty, Ogata \& Yano, 2007; Huang \& Yang, 2009; Hwang, Yang, Tsai \& Yang, 2009; Joiner, Nethercott, Hull \& Reid, 2006). PDAs were defined as pocket computers combined with wireless networks and web technology, in order to carry and use the information resources of the Internet, anytime, anywhere (Churchill \& Churchill, 2008; Tatar, Roschelle, Vahey \& Penuel, 2003), such as Palm Company's Palm pocket computer and Hewlett-Packard Company's $i P A Q$ pocket PC. According to the features of PDAs, these studies presented the interfaces of their $\mathrm{u}$ learning systems, which are similar to those on web pages such as applying Internetbased tools in PDAs for supporting u-learning environments. Besides, Cheung and Hew (2009) indicated that mobile devices such as mobile phones and PDAs have the features of wireless access and are light enough to place in one's palm, and therefore might influence how learners learn. Therefore, the role of PDAs has attracted attention in u-learning environments because of their potential to enhance ubiquitous learning practice.

While learners may have more opportunities to learn by using PDAs in u-learning environments, their attitudes and self-efficacy regarding PDAs for u-learning should become an important research issue, just as they are in other learning environments. For example, Wang and Wang (2008) explored students' self-efficacy regarding mobile devices, such as PDAs and handheld computers for mobile computing. However, their instrument was designed for college or advanced students, not for elementary students. Besides, few studies have explored learners' attitudes and self-efficacy of using PDAs particularly for u-learning. As attitudes and self-efficacy of using PDAs for u-learning are relatively new issues and elementary school students have gradually become a group of $\mathrm{u}$-learning users in Taiwan, investigating their attitudes and selfefficacy of using PDAs for u-learning is necessary for educational researchers.

Therefore, the purpose of this study was to develop a PDA Attitude Survey (PAS) and a PDA Self-efficacy Survey (PSS). Also, the relationships between students' attitudes to using PDAs for u-learning (called "PDA attitudes") and their self-efficacy of using PDAs for u-learning (called "PDA self-efficacy") were examined. The present study also analysed how some background variables, including gender, grade and Internet experience, have played a role in their attitudes and self-efficacy of using PDAs for $\mathrm{u}$ learning. 
By gathering questionnaire data from a group of elementary school students with experience in using PDAs for u-learning, the present study addressed the following research questions:

1. What are the students' PDA attitudes?

2. Is there any gender difference in the students' PDA attitudes?

3. Is there any grade difference in the students' PDA attitudes?

4. What is the effect of the students' Internet usage experience on their PDA attitudes?

5. What is the PDA self-efficacy expressed by the students?

6. Is there any gender difference in the students' PDA self-efficacy?

7. Is there any grade difference in the students' PDA self-efficacy?

8. What is the effect of the students' Internet experience on their PDA self-efficacy?

9. What are the relationships (if any) between students' PDA attitudes and their PDA self-efficacy?

\section{Methods}

\section{Sample}

The sample of this study comprised 414 third-grade to sixth-grade students (age 9-12 years; consisting of 200 males and 214 females) from an elementary school in central Taiwan, who had experience of using PDAs for u-learning. Few students had out of school experience of using PDA-related functions. All of them participated in a large ulearning research project utilizing PDAs in the school library, which involved searching for books (Hwang, Ye, Lin, Peng \& Lyu, 2008) and in the school campus which involved observing campus plants (Hwang, Li, Lai, Wang, Hong, Wu \& Chen, 2009). These u-learning activities were implemented once per semester, for one hour, and had already completed twice. After the second u-learning activity had been completed, the students' attitudes and their self-efficacy of using PDAs for u-learning were investigated. The students were from two major grade groups: 204 third and fourthgraders (age 9-10 years; i.e., lower-graders), and 210 fifth and sixth-graders (age 11-12 years; i.e., higher-graders). The survey data for this study were collected during January 2009.

\section{Instrument}

To assess the students' attitudes and their self-efficacy of using PDAs for u-learning, this study developed two instruments: the PDA attitudes survey (PAS) and the PDA selfefficacy survey (PSS).

The PDA Attitudes Survey (PAS), implemented in this study, adapted the main items from Tsai, Lin and Tsai's (2001) Internet attitude scale, and added new items. Tsai et al. (2001) proposed the following four scales: affection, perceived usefulness, perceived control, and behaviour, with a total of 18 items. In this study, the authors mainly used these items, rewriting the term "Internet" as "PDA", and specifying the context of ulearning. For example, the item "The Internet helps me acquire relevant information I need" was rewritten as "In the u-learning environment, the PDA helps me acquire relevant information I need". Moreover, the authors developed 8 additional items which addressed the special features of PDAs for u-learning. For example, the items "In the u-learning environment, the PDA provides me with another way to learn" and "In the u-learning environment, the PDA helps me to promote the process of learning" 
focused on the function of learning content sharing and interaction provided by the PDAs. Hence, based on Tsai et al.'s (2001) 18 items and 8 new items, the initial version of the PAS included 26 items. All of the items were undertaken in Chinese. The translation of items into English was completed by one of the authors, and the remaining authors validated the translation. In addition, the survey items were presented with bipolar strongly disagree/strongly agree statements in a five-point Likert scale, from 1 (strongly disagree) to 5 (strongly agree). Moreover, the items stated in reverse were scored in a reverse way. That is, students with higher average scores on the PAS scales were more likely to hold more positive attitudes toward using PDAs for u-learning; on the contrary, those with lower average scores may express more negative attitudes toward using PDAs for u-learning. A detailed description of the four scales is as follows:

1. Perceived usefulness scale measures students' perspectives of the positive impacts of the PDA on individuals.

2. Affection scale measures students' feelings and anxiety when using PDAs.

3. Behaviour scale measures students' degree of willingness to actually use a PDA.

4. Perceived control scale measures students' confidence in their independent control of a PDA.

As described earlier, according to the features of PDAs, the most popular presentation method on PDAs is similar to that on web pages. Hence, the PDA Self-efficacy Survey (PSS) implemented in this study adapted the main items from Tsai and Tsai's (2003) Internet self-efficacy scale, and added new items. Tsai and Tsai (2003) proposed nine items of Internet self-efficacy. In this study, the authors mainly used these items, but rewrote them for the context of using PDAs in a u-learning context, and renamed the scale as the Internet self-efficacy scale of using PDAs for u-learning. For example, the item "I think I know how to use a Web browser" was rewritten as "In the u-learning context, I think I know how to use a Web browser on a PDA". Moreover, the authors developed four additional items which addressed the general features of PDAs for ulearning, called general PDA self-efficacy. For example, the items "In the u-learning context, I think I know how to open a document on a PDA" and "In the u-learning context, I think I can read the content on the screen of a PDA" focused on the functions provided by the PDAs.

Hence, based on Tsai and Tsai's (2003) nine items and four new items, the initial version of the PSS included 13 items. Again, all of the items were undertaken in Chinese. The translation of items into English was completed by one of the authors, and the remaining authors validated the translation. In addition, the items were presented with bipolar strongly unconfident/strongly confident statements in a fivepoint Likert scale, from 1 (strongly unconfident) to 5 (strongly confident). That is, students with higher average scores on the PSS scales were more likely to have higher confidence in using PDAs for u-learning; on the contrary, those with lower average scores may express lower confidence in using PDAs for u-learning. A detailed description of the two scales is as follows:

1. Internet self-efficacy scale of using PDAs (abbreviated as Internet self-efficacy) measures the students' confidence in their use of Internet-based tools in PDA supported u-learning environments.

2. General PDA self-efficacy scale measures the students' confidence in their use of PDAs in general for u-learning, such as using PDA-related tools. For example, "I think I know how to open a document on a PDA." 


\section{Results}

\section{Factor analysis}

To clarify the structure of the students' attitudes toward PDAs for u-learning, this study applied exploratory factor analysis, principal component analysis with varimax rotation, to explore the factor structure among these items. An item within a factor was retained only when its loading was greater than 0.50 on the relevant factor and less than 0.50 on the non-relevant factor. Table 1 presents the results derived from the factor analysis method, revealing four factors among the items, namely "perceived usefulness scale," "affection scale," "behaviour scale" and "perceived control scale", which accounted for $68 \%$ of the total variance explained.

Table 1: Rotated factor loadings and Cronbach's alpha values for the four factors (scales) of PDA attitudes $(n=414)$

\begin{tabular}{|c|c|c|c|c|c|c|}
\hline Factor & & Item & $\begin{array}{c}\text { Factor } \\
1\end{array}$ & $\begin{array}{c}\text { Factor } \\
2\end{array}$ & $\begin{array}{c}\text { Factor } \\
3\end{array}$ & $\begin{array}{c}\text { Factor } \\
4\end{array}$ \\
\hline \multirow{6}{*}{$\begin{array}{l}\text { Factor 1: } \\
\text { Perceived } \\
\text { usefulness, } \\
\text { alpha }=0.88\end{array}$} & & $\begin{array}{l}\text { In the u-learning environment, a PDA can help } \\
\text { me to attain more ideas. }\end{array}$ & 0.84 & & & \\
\hline & 2. & $\begin{array}{l}\text { In the u-learning environment, a PDA is helpful } \\
\text { for my learning. }\end{array}$ & 0.77 & & & \\
\hline & 3. & $\begin{array}{l}\text { In the u-learning environment, the materials are } \\
\text { clarified when using a PDA. }\end{array}$ & 0.77 & & & \\
\hline & 4. & $\begin{array}{l}\text { In the u-learning environment, a PDA can } \\
\text { enhance my desire to learn. }\end{array}$ & 0.74 & & & \\
\hline & & $\begin{array}{l}\text { In the u-learning environment, a PDA provides } \\
\text { me with another way to learn. }\end{array}$ & 0.73 & & & \\
\hline & 6. & $\begin{array}{l}\text { In the u-learning environment, a PDA can allow } \\
\text { me to do more interesting and imaginative work. }\end{array}$ & 0.70 & & & \\
\hline \multirow[t]{4}{*}{$\begin{array}{l}\text { Factor 2: } \\
\text { Affection, } \\
\text { alpha }=0.84\end{array}$} & 7. & $\begin{array}{l}\text { In the u-learning environment, I hesitate to use a } \\
\text { PDA because of my fear of making mistakes I } \\
\text { can't correct. }^{*}\end{array}$ & & 0.87 & & \\
\hline & 8. & $\begin{array}{l}\text { In the u-learning environment, a PDA makes me } \\
\text { feel uncomfortable. }{ }^{*}\end{array}$ & & 0.87 & & \\
\hline & & $\begin{array}{l}\text { In the u-learning environment, I feel bored using } \\
\text { a PDA.* }\end{array}$ & & 0.76 & & \\
\hline & 10. & $\begin{array}{l}\text { In the u-learning environment, I am not good at } \\
\text { talking about the experiences of using a PDA.* }\end{array}$ & & 0.72 & & \\
\hline \multirow{3}{*}{$\begin{array}{l}\text { Factor 3: } \\
\text { Behaviour, } \\
\text { alpha }=0.86\end{array}$} & 11. & $\begin{array}{l}\text { In the u-learning environment, I hope to have } \\
\text { regular time to use PDAs at school. }\end{array}$ & & & 0.79 & \\
\hline & 12. & $\begin{array}{l}\text { In the u-learning environment, if I have the } \\
\text { opportunity to use a PDA, I am willing to take it. }\end{array}$ & & & 0.75 & \\
\hline & 13. & $\begin{array}{l}\text { In the u-learning environment, I hope to apply } \\
\text { PDAs in various learning activities. }\end{array}$ & & & 0.65 & \\
\hline \multirow{3}{*}{$\begin{array}{l}\text { Factor 4: } \\
\text { Perceived } \\
\text { control, } \\
\text { alpha }=0.55\end{array}$} & 14. & $\begin{array}{l}\text { In the u-learning environment, I need an } \\
\text { experienced person nearby when I use a PDA.* }\end{array}$ & & & & 0.78 \\
\hline & 15. & $\begin{array}{l}\text { In the u-learning environment, I need someone to } \\
\text { tell me the best way to use a PDA.* }\end{array}$ & & & & 0.75 \\
\hline & 16. & $\begin{array}{l}\text { In the u-learning environment, I can use a PDA } \\
\text { independently, without the assistance of others. }\end{array}$ & & & & 0.61 \\
\hline \multicolumn{3}{|l|}{$\%$ of variance } & 36.90 & 17.24 & 8.96 & 4.98 \\
\hline
\end{tabular}


Accordingly, the initial 26 items were reduced to 16 items. The internal reliability (alpha) coefficients of the three factors are $0.88,0.84,0.86$ and 0.55 , respectively; moreover, for the complete item set, the alpha coefficient is 0.83 . However, Hatcher and Stepanski (1994) claimed that a Cronbach alpha coefficient can be recognised and accepted for statistical consideration even as low as 0.55 . Therefore, these scales were deemed to be sufficiently reliable for assessing students' attitudes toward PDAs for ulearning.

In addition, to clarify the structure of the students' self-efficacy of using PDAs for ulearning, this study also applied exploratory factor analysis, principal component analysis with varimax rotation, to explore the factor structure among these items. An item within a factor was retained only when its loading was greater than 0.50 on the relevant factor, and less than 0.50 on the non-relevant factor. Table 2 presents the results derived from the factor analysis method, revealing two factors among the items, namely "Internet self-efficacy scale of using PDAs" and "general PDA selfefficacy scale", which accounted for $67 \%$ of the total variance explained.

Table 2: Rotated factor loadings and Cronbach's alpha values for the two factors (scales) of PDA self-efficacy $(n=414)$

\begin{tabular}{|c|c|c|c|c|}
\hline \multirow{6}{*}{\begin{tabular}{|l}
\multicolumn{1}{c|}{ Factor } \\
Factor 1: \\
Internet self- \\
efficacy of \\
using PDAs, \\
alpha $=0.89$
\end{tabular}} & & Item & Factor 1 & Factor 2 \\
\hline & & $\begin{array}{l}\text { In the u-learning context, I think I can download a figure } \\
\text { from the Internet using a PDA. }\end{array}$ & 0.84 & \\
\hline & 2. & $\begin{array}{l}\text { In the u-learning context, I think I can copy content from the } \\
\text { Internet and paste it into a document using a PDA. }\end{array}$ & 0.83 & \\
\hline & 3. & $\begin{array}{l}\text { In the u-learning context, I think I can key in a website } \\
\text { address to enter the website using a PDA. }\end{array}$ & 0.78 & \\
\hline & & $\begin{array}{l}\text { In the u-learning context, I think I can check a hyperlink to } \\
\text { enter another website using a PDA. }\end{array}$ & 0.75 & \\
\hline & & $\begin{array}{l}\text { In the u-learning context, I think I know how to use a Web } \\
\text { homepage like 'Yahoo!' using a PDA. }\end{array}$ & 0.70 & \\
\hline \multirow{4}{*}{$\begin{array}{l}\text { Factor 2: } \\
\text { General } \\
\text { PDA self- } \\
\text { efficacy, } \\
\text { alpha =0.81 }\end{array}$} & 6. & $\begin{array}{l}\text { In the u-learning context, I think I can read the content on the } \\
\text { screen using a PDA. }\end{array}$ & & 0.84 \\
\hline & & $\begin{array}{l}\text { In the u-learning context, I think I can click the link or button } \\
\text { to enter a new step using a PDA. }\end{array}$ & & 0.75 \\
\hline & 8. & $\begin{array}{l}\text { In the u-learning context, I think I can know where I am } \\
\text { using a PDA. }\end{array}$ & & 0.75 \\
\hline & & $\begin{array}{l}\text { In the u-learning context, I think I can enter words into a } \\
\text { document using a PDA. }\end{array}$ & & 0.70 \\
\hline \multicolumn{3}{|l|}{$\%$ of variance } & 54.25 & 12.76 \\
\hline
\end{tabular}

Accordingly, the initial 13 items were reduced to 9 items. The internal reliability (alpha) coefficients of the two factors are 0.89 , and 0.81 , respectively; moreover, for the complete item set, the alpha coefficient is 0.89 . Therefore, these scales were deemed to be sufficiently reliable for measuring students' confidence in using PDAs for ulearning.

\section{Students' scores on the PAS and the PSS}

Table 3 shows the students' average scores and standard deviations on the PAS scales. The students scored highest on the behavioural scale, followed by the perceived usefulness scale, and the affection scale, with the lowest score on the perceived control scale. This implies that the students had high willingness to utilise the PDAs, and have 
positive perspectives toward PDAs for $u$-learning. The lowest average score on the perceived control scale suggested that some of the students might experience certain difficulties in controlling a PDA.

Table 3: Students' scores on the scales of the PDA attitude survey and the PDA self-efficacy survey

\begin{tabular}{|l|l|c|c|c|}
\hline \multicolumn{1}{|c|}{ Scale } & Items & Mean & SD \\
\hline \multirow{2}{*}{$\begin{array}{l}\text { PDA attitude } \\
\text { survey (PAS) }\end{array}$} & Perceived usefulness & 6 & 4.12 & 0.84 \\
\cline { 2 - 5 } & Affection & 4 & 3.97 & 1.04 \\
\cline { 2 - 5 } & Behaviour & 3 & 4.31 & 0.88 \\
\cline { 2 - 5 } & Perceived control & 3 & 2.88 & 1.02 \\
\hline $\begin{array}{l}\text { PDA self-efficacy } \\
\text { survey (PSS) }\end{array}$ & Internet self-efficacy of using PDAs & 5 & 3.75 & 1.08 \\
\cline { 2 - 5 } & General PDA self-efficacy & 4 & 4.31 & 0.79 \\
\hline
\end{tabular}

Table 3 also presents the students' average scores and standard deviations of the PSS scales. The students scored higher on the general PDA self-efficacy scale. This implies that they tended to have high confidence in using the PDAs for general purposes.

\section{Gender differences on PDA attitudes and PDA self-efficacy}

This study further compared the possible differences of the attitudes and self-efficacy of using PDAs for $\mathrm{u}$-learning between male and female students. Table 4 shows that the male and female students' scores on the PAS scales did not show significant differences, which implies that both male and female students tend to have similar attitudes toward using PDAs. However, the Internet self-efficacy scale of using PDAs expressed by the male students scored higher than that expressed by the female students $(p<0.01)$. That is, the male students expressed higher confidence in using the PDAs for Internet-related functions than the female students.

Table 4: Gender comparisons on the scales of the PDA attitude survey and the PDA self-efficacy survey

\begin{tabular}{|l|l|c|c|c|}
\hline \multicolumn{2}{|c|}{ Scale } & $\begin{array}{c}\text { Male }(\mathrm{n}=200) \\
(\text { mean, SD) }\end{array}$ & $\begin{array}{c}\text { Female (n=214) } \\
(\mathrm{mean}, \mathrm{SD})\end{array}$ & $t$ \\
\hline \multirow{2}{*}{$\begin{array}{l}\text { PDA attitude } \\
\text { survey (PAS) }\end{array}$} & Perceived usefulness & $4.07(0.93)$ & $4.17(0.74)$ & -1.14 \\
\cline { 2 - 5 } & Affection & $4.00(1.07)$ & $3.94(1.01)$ & 0.62 \\
\cline { 2 - 5 } & Behaviour & $4.29(0.91)$ & $4.32(0.84)$ & -0.43 \\
\cline { 2 - 5 } & Perceived control & $2.96(1.03)$ & $2.81(1.01)$ & 1.51 \\
\hline $\begin{array}{l}\text { PDA self-efficacy } \\
\text { survey (PSS) }\end{array}$ & Internet self-efficacy of using PDAs & $3.90(1.05)$ & $3.60(1.09)$ & $2.79^{* *}$ \\
\cline { 2 - 5 }${ }^{* *} p<0.01$ & $4.37(0.75)$ & $4.25(0.81)$ & 1.47 \\
\hline \multicolumn{3}{|l|}{} \\
\cline { 2 - 5 }
\end{tabular}

\section{The role of grade levels in PDA attitudes and PDA self-efficacy}

In this study, the third and fourth grade students were categorised as lower-graders, while the fifth and sixth grade students were categorised as higher-graders. This study further compared the possible differences of attitudes and self-efficacy of using PDAs between the lower-grade and higher-grade students. The $t$ test revealed that the students' scores on the PAS's scales of perceived usefulness, and behavioural and perceived control showed significant differences, as shown in Table 5. It was found that the students in the lower grades tended to have statistically higher scores on the perceived usefulness and behavioural scales than the students in the higher grades. It is plausible that the novelty of the PDAs might make the lower-graders likely to use 
them more frequently and to have more positive perspectives towards them. On the other hand, the students in the higher grades tended to have statistically higher scores on the perceived control scale than the students in the lower grades. It is plausible that the higher-graders had more confidence in their independent control of the PDAs than the lower-graders as they might be more sophisticated in using technology-related tools. However, the students in different grades did not show different perspectives toward the feeling of using PDAs (i.e. affection scale).

In addition, the $t$ test also revealed that the students' scores on the PSS general PDA self-efficacy scale show a significant difference, as shown in Table 5. It was found that students in the lower grades tended to have statistically higher scores on the general PDA self-efficacy scale than the students in the higher grades. However, the students of different grades did not show different levels of confidence in using PDAs regarding Internet-related functions.

Table 5: Students' PDA attitudes and PDA self-efficacy among groups with different grades

\begin{tabular}{|c|c|c|c|c|}
\hline & Scale & $\begin{array}{c}\text { Lower grade } \\
\quad(n=204) \\
(\text { mean, SD) }\end{array}$ & $\begin{array}{l}\text { Higher grade } \\
\quad(n=210) \\
(\text { mean, SD) }\end{array}$ & $t$ \\
\hline PDA attitude & Perceived usefulness & $4.25(0.74)$ & $3.99(0.90)$ & $3.19^{* *}$ \\
\hline survey (PAS) & Affection & $4.06(1.05)$ & $3.88(1.02)$ & 1.72 \\
\hline & Behaviour & $4.43(0.76)$ & $4.18(0.96)$ & $2.98^{* *}$ \\
\hline & Perceived control & $2.70(0.97)$ & $3.05(1.04)$ & $-3.60^{* * *}$ \\
\hline PDA self-efficacy & Internet self-efficacy of using PDAs & $3.66(1.10)$ & $3.83(1.05)$ & 1.67 \\
\hline survey (PSS) & General PDA self-efficacy & $4.39(0.72)$ & $4.23(0.84)$ & $2.14^{*}$ \\
\hline
\end{tabular}

\section{The role of Internet usage experiences on PDA attitudes and PDA self-efficacy}

In m-learning and u-learning, the most popular presentation method on mobile devices is similar to that on web pages. Hence, this study further investigated the effect of the students' Internet usage experience on their attitudes toward PDAs and their self-efficacy of using a PDA. The number of the students' online hours on average per day was defined as their Internet usage experience; hence, the students were divided into two groups of different Internet usage experience: less than 2 hours and more than 2 hours per day. Table 6 shows the analysis of the Internet usage experience groups and their attitudes and self-efficacy of using a PDA.

Table 6: Students' PDA attitudes and PDA self-efficacy among groups with different Internet experience

\begin{tabular}{|c|c|c|c|c|}
\hline & Scale & $\begin{array}{l}\text { Less than } 2 \\
\text { hours }(\mathrm{n}=314) \\
(\mathrm{mean}, \mathrm{SD})\end{array}$ & $\begin{array}{l}\text { More than } 2 \\
\text { hours }(\mathrm{n}=100) \\
\text { (mean, SD) }\end{array}$ & $t$ \\
\hline PDA attitude & Perceived usefulness & $4.10(0.83)$ & $4.16(0.86)$ & -0.60 \\
\hline survey (PAS) & Affection & $3.96(1.01)$ & $4.01(1.12)$ & -0.42 \\
\hline & Behaviour & $4.31(0.86)$ & $4.29(0.94)$ & 0.21 \\
\hline & Perceived control & $2.82(1.01)$ & $3.06(1.04)$ & $-2.09^{*}$ \\
\hline PDA self-efficacy & Internet self-efficacy of using PDAs & $3.67(1.08)$ & $3.97(1.05)$ & $-2.45^{\star}$ \\
\hline survey (PSS) & General PDA self-efficacy & $4.32(0.76)$ & $4.27(0.86)$ & 0.48 \\
\hline
\end{tabular}


The $t$ test revealed that Internet usage experience showed a significant effect on the PAS's perceived control scale and on the PSS's Internet self-efficacy scale of using PDAs. It was found that students with more experience of using the Internet tended to have higher scores on the scale of perceived control and Internet self-efficacy of using PDAs. That is, students' Internet usage experience enhances their confidence in controlling PDAs and using PDAs for Internet-related functions. However, the students' Internet usage experience was not related to the PAS's perceived usefulness, affection and behaviour scales or the PSS's general PDA self-efficacy scale.

\section{Correlation between PDA attitudes and PDA self-efficacy}

Tsai et al. (2001) and Wu and Tsai (2006) found that university students' attitudes toward the Internet were correlated with their Internet self-efficacy. Hence, this study also explored the correlation among students' attitudes and their self-efficacy of using PDAs, as shown in Table 7. The results indicate that the students' scores on the general PDA self-efficacy scale had the highest correlation with their scores on the affection scale $(\mathrm{r}=0.35, p<0.01)$, implying that the students with higher self-efficacy of using PDAs for general purposes tend to have less anxiety. Students' scores on the Internet self-efficacy scale of using PDAs had the highest correlation with their scores on the perceived control scale $(r=0.30, p<0.01)$, implying that students who had higher selfefficacy of using PDAs for Internet-related functions tended to have favorable attitudes toward independently controlling a PDA. In addition, the students' scores on the PSS's general PDA self-efficacy scale were all significantly correlated with their scores on the PAS scales $(p<0.01)$. This indicates that the students with higher confidence in using PDAs for general purposes tend to express more positive perspectives, less anxiety, better control and greater willingness to use PDAs. This also suggests that for predicting students' attitudes toward the use of PDAs in u-learning, students' confidence in using PDAs for general purposes is more important than their confidence in using PDAs for Internet-related functions.

Table 7: Correlation between students' PDA attitudes and their PDA self-efficacy

\begin{tabular}{|l|c|c|c|c|}
\hline \multicolumn{1}{|c|}{ Scale } & $\begin{array}{c}\text { Perceived } \\
\text { usefulness }\end{array}$ & Affection & Behaviour & $\begin{array}{c}\text { Perceived } \\
\text { control }\end{array}$ \\
\hline Internet self-efficacy of using PDAs & 0.10 & $0.13^{* *}$ & 0.08 & $0.30^{* *}$ \\
\hline General PDA self-efficacy & $0.27^{* *}$ & $0.35^{* *}$ & $0.24^{* *}$ & $0.26^{* *}$ \\
\hline${ }^{* *} p<0.01$ & \multicolumn{3}{|l}{} \\
\hline
\end{tabular}

\section{Discussion and conclusions}

In this study, PAS and PSS instruments were developed with satisfactory validity and reliability measures. By means of these two instruments, students scored lowest on the "perceived control" scale of the PAS. This result suggests that researchers should try to improve students' independent control of PDAs. Some gender, grade-level and Internet usage experience differences were also found. These results are discussed below.

This study investigated the possible differences of attitudes and self-efficacy toward PDAs between male and female students, but no significant gender difference was found except for a difference in the self-efficacy of using PDAs for Internet-related functions. That is, the male students were significantly more confident in their use of the PDA Internet-related functions than the female students. Therefore, researchers 
should pay more attention to enhancing female students' confidence in operating PDAs for performing Internet-related functions.

Moreover, this study also revealed that the higher-grade students tended to have more confidence in their independent control of the PDAs than the lower-grade students, but on the contrary, the lower-graders tended to be more willing to use the PDAs, expressed more positive perspectives of the PDAs, and tended to be more confident in their use of PDAs for general purposes. It seems that the novelty of PDAs might attract younger students' attention.

Tsai et al. (2001) and $\mathrm{Wu}$ and Tsai (2006) indicated that students with more Internet usage experience tended to have more positive Internet attitudes. In addition, Eastin and LaRose (2000) indicated a positive relationship between Internet self-efficacy and Internet usage experience. Hence, this study also examined the Internet usage experience differences among students' attitudes and self-efficacy of using PDAs. It was revealed that students' Internet usage experience did not result in significant differences in their positive perspectives, feelings and willingness to use PDAs, or their confidence in using PDAs for general purposes. However, it was found that the students' Internet usage experience had a significant effect on their independence in using the PDAs, as well as in using the PDAs for Internet-related functions. This finding shows that increasing students' Internet usage experience may enhance their perceived control of using PDAs and their confidence in using PDAs for Internetrelated functions. Future study is suggested to investigate the relationship between students' practical experience of using PDAs and their confidence in using them.

Moreover, this study explored the relationships between students' attitudes and their self-efficacy of using PDAs for u-learning. It was found that the students' confidence in using PDAs for general purposes was significantly positively correlated with their attitudes toward the PDAs, and the students' confidence in using PDAs for Internet functions was significantly positively correlated with their attitudes toward the PDAs, but only regarding their feelings and their perceived control of the PDAs. Therefore, when interpreting students' attitudes toward using PDAs for u-learning, their confidence in using them for general purposes is more important than their confidence in them for Internet functions.

Several studies have revealed that learners' attitudes and self-efficacy regarding information technology influence their usage, and therefore might influence how they learn and their learning performances (e.g. Susskind, 2008; Tsai \& Tsai, 2003; Peng et al., 2006; Wu \& Tsai, 2006). For example, Tsai and Tsai (2003) found that students with higher Internet self-efficacy may accomplish their tasks in a better way than students with lower Internet self-efficacy in an Internet-based learning task. Therefore, investigating students' attitudes and self-efficacy toward PDAs may be critical prerequisites for u-learning activities which use PDAs as mobile devices. In the future, studies may be conducted to explore how students' attitudes and self-efficacy toward PDAs influence their behaviours, learning processes and learning performances in $\mathrm{u}^{-}$ learning activities. In addition, there is also a need for some training courses to improve elementary students' attitudes and self-efficacy regarding the use of PDAs for u-learning. 


\section{Acknowledgments}

This study is supported in part by the National Science Council, Taiwan under grant numbers NSC 96-2511-S-011-002-MY3 and NSC 98-2631-S-011-001.

\section{References}

Cheung, W. S. \& Hew, K. F. (2009). A review of research methodologies used in studies on mobile handheld devices in K-12 and higher education settings. Australasian Journal of Educational Technology, 25(2), 153-183. http:/ / www.ascilite.org.au/ajet/ajet25/cheung.html

Chu, R. J. \& Tsai, C. C. (2009). Self-directed learning readiness, Internet self-efficacy, and preferences for constructivist Internet-based learning environments among higher aged adults. Journal of Computer Assisted Learning, 25(5), 489-501.

Churchill, D. \& Churchill, N. (2008). Educational affordances of PDAs: A study of a teacher's exploration of this technology. Computers $\mathcal{E}$ Education, 50(4), 1439-1450.

Dyson, L. E., Litchfield, A., Lawrence, E., Raban, R. \& Leijdekkers, P. (2009). Advancing the mlearning research agenda for active, experiential learning: Four case studies. Australasian Journal of Educational Technology, 25(2), 250-267. http: / / www.ascilite.org.au/ajet/ajet25/dyson.html

Eastin, M. S. \& LaRose R. (2000). Internet self-efficacy and the psychology of the digital divide. Journal of Computer-Mediated Communication, 6(1). http:/ / jcmc.indiana.edu/vol6/issue1/ eastin.html

El-Bishouty, M. M., Ogata, H. \& Yano, Y. (2007). PERKAM: Personalized knowledge awareness map for computer supported ubiquitous learning. Educational Technology E Society, 10(3), 122 134. http://www.ifets.info/journals/10_3/9.pdf

Federico, P. A. (2000). Learning styles and students attitudes toward various aspects of networkbased instruction. Computers in Human Behavior, 16(4), 359-379.

Hatcher, L. \& Stepanski, E. J. (1994). A step-by-step approach to using the SAS system for univariate and multivariate statistics. Cary, NC: SAS Institute.

Huang, A. F. M. \& Yang, S. J. H. (2009). Situational mashups for ubiquitous learning. International Journal on Digital Learning Technology, 1(3), 245-265.

http: / / ijdlt.org / download.php?dir=papers\&filename=00052010-02-_ijdlt3-6_.pdf

Hwang, G. H., Li, L. M., Lai, N. L., Wang, H. Y., Hong, P. J., Wu, J. R. \& Chen, B. Y. (2009). Botanical garden navigation using adaptive u-learning system. In Proceedings of the 13 th Global Chinese Conference on Computers in Education (GCCCE ). Taipei, Taiwan, 25-28 May.

Hwang, G. H., Ye, J. H., Lin, K. Y., Peng, R. S. \& Lyu, J. C. (2008). A library guide system combining mobile, sensing, and voice technologies and the influence factors' analysis of its usage satisfaction. In Proceedings of the International Conference on Computer and Network Technologies in Education (CNTE). Hsinchu, Taiwan, 30-31 October.

Hwang, G. J., Tsai, C. C. \& Yang, S. J. H. (2008). Criteria, strategies and research issues of contextaware ubiquitous learning. Educational Technology E Society, 11(2), 81-91. http:/ / www.ifets.info/journals/11_2/8.pdf

Hwang, G. J., Yang, T. C., Tsai, C. C. \& Yang, S. J. H. (2009). A context-aware ubiquitous learning environment for conducting complex science experiments. Computers $\mathcal{E}$ Education, 53(2), 402413. 
Joiner, R., Nethercott, J., Hull, R. \& Reid, J. (2006). Designing educational experiences using ubiquitous technology. Computers in Human Behavior, 22(1), 67-76.

Liaw, S. S. (2002). An Internet survey for perceptions of computers and the World Wide Web: relationship, prediction, and difference. Computers in Human Behavior, 18(1), 17-35.

Ogata, H. \& Yano, Y. (2004). Knowledge awareness map for computer-supported ubiquitous language-learning. In J. Roschelle, T. W. Chan, Kinshuk \& S. J. H. Yang (Eds.), Proceedings of the 2nd IEEE International Workshop on Wireless and Mobile Technologies in Education, WMTE'04 (pp. 19-26). JungLi, Taiwan, 23-24 March.

Oral, B. (2008). The evaluation of the student teachers' attitudes toward Internet and democracy. Computers \& Education, 50(1), 437-445.

Peng, H., Tsai, C. C. \& Wu, Y. T. (2006). University students' self-efficacy and their attitudes toward the Internet: The role of students' perceptions of the Internet. Educational Studies, 32(1), 73-86.

Susskind, J. E. (2008). Limits of PowerPoint's power: Enhancing students' self-efficacy and attitudes but not their behavior. Computers $\mathcal{E}$ Education, 50(4), 1228-1239.

Tatar, D., Roschelle, J., Vahey, P. \& Penuel, W. R. (2003). Handhelds go to school: Lessons learned. IEEE Transaction on Computer, 36(9), 58-65.

Torkzadeh, G., Thomas, P. \& Dyke, V. (2002). Effects of training on Internet self-efficacy and computer user attitudes. Computers in Human Behavior, 18(5), 479-494.

Tsai, C. C., Lin, S. S. J. \& Tsai, M. J. (2001). Developing an Internet attitude scale for high school students. Computers \& Education, 37(1), 41-51.

Tsai, M. J. \& Tsai, C. C. (2003). Information searching strategies in web-based science learning: The role of Internet self-efficacy. Innovations in Education and Teaching International, 40(1), 4350.

Wang, Y. S. \& Wang, H. Y. (2008). Developing and validating an instrument for measuring mobile computing self-efficacy. CyberPsychology E Behavior, 11(4), 405-413.

Wu, Y. T. \& Tsai, C. C. (2006). University students' Internet attitudes and Internet self-efficacy: A study at three universities in Taiwan. CyberPsychology $\mathcal{E}$ Behavior, 9(4), 73-86.

Pei-Shan Tsai (author for correspondence)

Graduate Institute of Engineering

National Taiwan University of Science and Technology

\#43, Sec.4, Keelung Road, Taipei, 106, Taiwan

Email: D9622305@mail.ntust.edu.tw

Chin-Chung Tsai

Graduate Institute of Digital Learning and Education and

Graduate Institute of Engineering

National Taiwan University of Science and Technology

\#43, Sec.4, Keelung Road, Taipei, 106, Taiwan

Email: cctsai@mail.ntust.edu.tw Web: http: / / www.cctsai.net/

Gwo-Haur Hwang

Department of Information Technology

Ling Tung University

1, Lingtung Road, Taichung, 408, Taiwan

Email: ghhwang@mail.ltu.edu.tw 